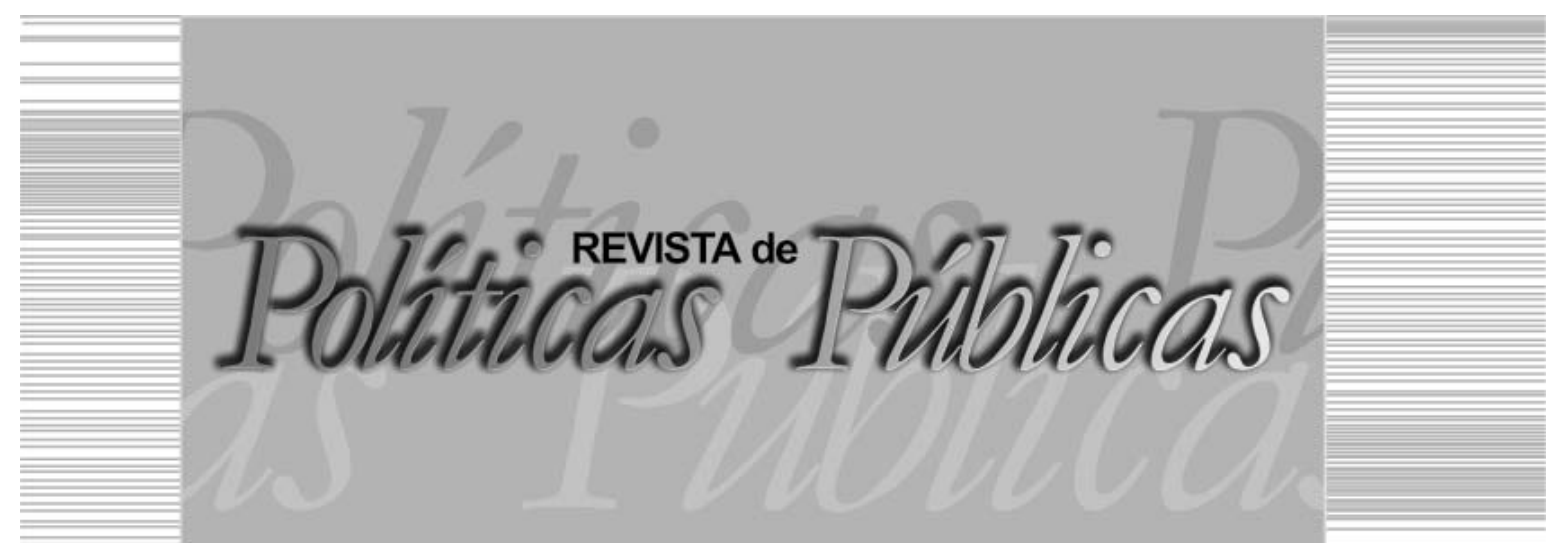

\title{
PARA ONDE CAMINHA A FORMAÇÃO DOCENTE?
}

\author{
Ilma Vieira do Nascimentol \\ Universidade Federal do Maranhão (UFMA) \\ Maria Alice Melo $^{2}$ \\ Universidade Federal do Maranhão (UFMA) \\ Maria Núbia Barbosa Bonfim ${ }^{3}$ \\ Universidade Federal do Maranhão (UFMA)
}

\begin{abstract}
Resumo
Com base em pesquisas desenvolvidas no PPGE/UFMA, o artigo discute a formação de professores da educação básica com foco no Plano Nacional de Formação de Professores da Educação Básica - PARFOR, realizado pela UFMA sob a denominação de PROFEBPAR. Apresenta o contexto de seu surgimento quando ganha dimensão nacional o interesse pela formação de professores enquanto expressão de uma política que se desenvolve à luz de orientações de cunho neoliberal a requerer reestruturação do Estado e, particularmente, da educação. Evidencia que a institucionalização dessa política, em 2009, objetiva conferir organicidade às ações institucionais, a partir daí sob a regulação da Capes. Nesse contexto, questiona o caráter emergencial desse Programa de

1 Pedagoga. Doutora em Educação. Professora do Programa de Pós-Graduação em Educação (PPGE) da Universidade Federal do Maranhão (UFMA) | E-mail: ilmavieira13@gmail. com

2 Pedagoga. Doutora em Educação. Professora do Curso de Pedagogia e do Programa de Pós-Graduação em Educação (PPGPE) da Universidade Federal do Maranhão (UFMA) | E-mail: ma.melo@terra.com.br

3 Pedagoga. Doutora em Ciências da Educação. Professora do Programa de Pós-Graduação em Educação (PPGPE) da Universidade Federal do Maranhão(UFMA)|E-mail: bonfim@ elo.com.br | Universidade Federal do Maranhão - UFMA | Cidade Universitária Dom Delgado | Av. dos Portugueses, n. 1966, Bacanga, São Luís/MA | CEP: 65085-580
\end{abstract}


formação de professores, em face da própria sistemática de sua realização e aos, ainda, inúmeros problemas a marcar a educação no Estado do Maranhão. Palavras-chave: Formação de professores, cursos emergenciais, Parfor.

\title{
WHERE IS THE TEACHERS' FORMATION GOING?
}

\begin{abstract}
Based in researches developed in PPGE/UFMA, the article discusses the formation of basic education teachers with focus in the National Plan for the Training of Basic Education Teachers - PARFOR(PT/BR), made by UFMA under the denomination of PROFEBPAR(PT/BR). Presents the context of its appearance as it gains national dimension interest for the formation of teachers as expression of a policy that develop itself at the light of neoliberal orientations to require reestructure of the State and, particularly, education. Highlights that the institutionalization of this policy, in 2009, aims to check oganicity to institutional actions, under the regulation of Capes. In this context, question the emergencial character of this teachers' formation program, under its own systematic of realization and to those, still, Innumerable problems that mark the education in the State of Maranhão.
\end{abstract}

Key words: Teachers' formation, emergencial courses, Parfor.

\section{INTRODUÇÃO}

Da última década do século XX para cá, está em implementação um conjunto de medidas que caracterizam as reformas do Estado brasileiro em conformidade com mudanças em processo no mundo capitalista. São mudanças que se estendem ao campo educacional por meio de aparatos legais, cujo desdobramento incide na formação de professores.

Tais desdobramentos se expressam, na primeira década do século XXI, na instituição de uma política nacional voltada para a formação docente que tem a CAPES como órgão regulador, cuja implementação se dá em regime de colaboração com os entes federados.

Neste texto problematizamos a política nacional de formação de profissionais do magistério da educação básica tal como se expressa no Programa de Formação de Professores da Educação Básica (PROFEBPAR), desenvolvido na Universidade Federal do Maranhão (UFMA). 


\subsection{Políticas de formação docente no Brasil: breve contextualização}

Dos anos de 1960 em diante, a educação superior no Brasil veio se configurando sob nítidos traços de um capitalismo que, cumprindo a tendência de universalização, que lhe é inerente, estende a sua influência até ao âmbito da organização do Estado, o que se torna marcante a partir dos anos 1990, no governo de Fernando Henrique Cardoso (FHC). A reforma do Estado brasileiro e a concomitante reforma da educação tornam-se uma necessidade relevante nos marcos do sistema capitalista que se irradia, agora mais do que antes, orientadas ambas as reformas pela mediação econômica, cultural e política de agências multilaterais (Banco Mundial [BM], Fundo Monetário Internacional [FMI], Banco Internacional para Reconstrução e Desenvolvimento [BIRD], Organização das Nações Unidas [ONU], Organização das Nações Unidas para a educação, a ciência e a cultura [UNESCO]). Ao analisar a reconfiguração da educação e a reforma do Estado brasileiro, Silva Jr. (2003, p. 61) as entende "[...] direcionadas por uma razão instrumental, que se constitui no epicentro de um processo de mercantilização do trabalho imaterial em geral, e em particular, da esfera educacional em seu nível superior."

As ideias desenvolvidas por esse autor ajudam-nos a entender o conhecido documento do BM, do ano de 1994, sob o título $\mathrm{O}$ ensino superior: as lições derivadas da experiência, em que ficam explicitadas as diretrizes desse banco para a educação superior dos países em desenvolvimento no intuito de alcançar as metas de qualidade, eficiência e equidade nesse nível de ensino. Entre as diretrizes, merecem destaque as recomendações sobre o fomento a ser dado a uma maior diferenciação das instituições de educação superior, públicas e privadas, e o impulso que os governos devem dar ao desenvolvimento da educação superior privada, na medida em que, segundo aquele órgão, estas instituições podem responder com eficácia e flexibilidade às transformações de uma demanda em expansão e, assim, complementar as ações das instituições estatais.

Embora já se verificasse antes dessa década, a educação superior no Brasil tende a uma maior expansão a partir da promulgação da Lei de Diretrizes e Bases da Educação Nacional (LDB) - Lei ${ }^{\circ}$ 9.394, de 20 de dezembro de 1996. Nesse ano, havia 922 instituições de educação superior (IES) em todo o território nacional, sendo 211 públicas e 711 privadas (BRASIL, 1996). Em 2011, das 2.365 
IES então existentes, 284 eram públicas e 2.081 privadas (BRASIL, 2011), o que demonstra o considerável salto, em 15 anos, de 192,7\% das instituições privadas contra os irrisórios 34,6\% das instituições públicas. Evidentemente, esta expansão das IES é acompanhada pelo aumento das matrículas por força de pressões do mercado de trabalho que exige maior escolaridade das pessoas, embora nem todas venham a ser por ele absorvidas. Assim, em 2011, do total de 6.739.689 matrículas em cursos de graduação presencial e a distância, 4.966.374 encontram-se em instituições privadas, enquanto nas públicas apenas 1.773.315, segundo dados do INEP (BRASIL, 2011).

Os aspectos interrelacionados da expansão da educação superior, acima mencionados, podem ser entendidos como uma expressão da configuração que toma esse nível de ensino no país na medida em que a expansão se dá pela proliferação de diferentes cursos e tipos de instituições, tais como preconizados na LDB e em legislações complementares. Multiplicam-se instituições isoladas privadas que oferecem uma variedade de cursos, como os sequenciais, de pós-graduação lato sensu sem a exigência da manutenção de cursos de graduação, e até franquias que se tornam comuns segundo a lógica do mercado. O crescimento do número de IES no estado do Maranhão dá-nos uma breve configuração da rapidez do processo de expansão dessas instituições no Brasil, tomando-se como referência o ano da promulgação da LDB. Em 1996, havia nesse estado 4 IES, sendo 3 públicas (duas universidades e um estabelecimento isolado, o antigo CEFET) e uma privada. Em 2011, das 30 IES 3 são públicas, mantendo o formato precedente, enquanto 27 são privadas, das quais uma é um centro universitário e 26 são faculdades isoladas (BRASIL 2011).

Nesse contexto, cresce o interesse no âmbito da reforma do Estado e da educação pela implementação de políticas voltadas para a formação de professores, na medida em que se foi sedimentando a centralidade da formação desses profissionais como uma condição para levar a termo as reformas de cunho neoliberal, em implementação desde o final dos anos 80 . Porém, é bom lembrar, nesse espaço movimentam-se também outras concepções políticas e movimentos sociais em oposição àquelas orientações. Freitas $(1999$, p. 18) analisa que 


\section{PARA ONDE CAMINHA A FORMAÇÃO DOCENTE?}

[...] no quadro das políticas educacionais neoliberais e das reformas educativas, a educação constitui-se em elemento facilitador importante dos processos de acumulação capitalista e, em decorrência, a formação de professores ganha importância estratégica para a realização dessas reformas no âmbito da escola e da educação básica. $^{2}$

O conjunto da legislação que orienta a educação nacional, criada a partir da década de 1990, insere-se nas reformas empreendidas. No âmbito da legislação merece destacar, além da LDB e de outros instrumentos legais, o Fundo de Manutenção e Desenvolvimento do Ensino Fundamental e de Valorização do Magistério (FUNDEF) (Lei n. 9.494, de 10 de setembro de 1996), substituído posteriormente pelo Fundo de Manutenção e Desenvolvimento da Educação Básica e de Valorização dos Profissionais da Educação (FUNDEB) (Lei n. 11.494, de 20 de junho de 2007), que "[...] instituíram mecanismo regular, sustentável e mais equitativo de manutenção e desenvolvimento do ensino.", como analisam Gatti, Barretto e André (2011, p. 33), com a destinação de 60\% dos seus recursos para a remuneração e aperfeiçoamento dos professores e demais profissionais da educação em exercício no setor público.

Essas formas de regulação de recursos destinados, prioritariamente, para os professores da educação básica, ao propiciar condições para a formação em nível superior desses profissionais propiciam o crescimento de matrículas em IES públicas, embora tal não ocorra em todos os estados. A região Nordeste registra, em 2011, 1.326.656 matrículas em cursos de graduação presenciais e a distância. Dessas, 220.199 estão em cursos de licenciatura na rede pública e 110.686 na rede privada de ensino superior, embora no cômputo geral o setor privado absorva um quantitativo maior de alunos matriculados (812.444) do que o setor público (514.212). O Maranhão reproduz esta ocorrência, tanto que no ano de 2011, das 111.285 matrículas em cursos de graduação presenciais e a distância, 24.066 estão em cursos de licenciatura em instituições públicas, registrando-se nas instituições privadas 11.722 matrículas em cursos dessa natureza (BRASIL, 2011). Cumpre, portanto, enfatizar que os desdobramentos que tomam as reformulações iniciadas pela LDB, reforçadas por legislação complementar, se expressam em vários Programas criados pelo MEC, a partir de então, que tomam como foco a formação docente. 
Embora na década de 90 houvesse ações do MEC em consonância com as reformas em curso por meio da criação de Programas direcionados para a formação docente, é no novo milênio que se registra um volume maior de Programas e se incrementam outras ações ligadas à formação docente, não necessariamente originadas no âmbito do MEC ou do governo federal. Estas ações inscrevem-se na luta dos educadores pela qualidade da educação pública que, como nos diz Saviani (2007, p. 1243), "[...] se mantém com grandes dificuldades neste início do século XXI, na forma de resistência às políticas e reformas em curso e na reivindicação por melhores condições de ensino e de trabalho para os profissionais da educação."

Assim, a centralidade que passa a ocupar a formação de professores no rol das políticas de expansão da educação superior e da escolarização de modo geral vem carregada de acentuado apelo à melhoria da qualidade da educação básica, porém com entendimento diferenciado daquele defendido nos movimentos históricos dos educadores, como frisou Saviani. Como nos lembra Freitas (2007), a expansão sem controle dos Cursos Normais Superiores e Pedagogia, além de cursos de licenciatura, logo após a promulgação da LDB e sob o respaldo dessa lei, desenvolvidos em sua maioria em instituições privadas, não se fez acompanhar por uma formação de qualidade pelo descompromisso dominante em quase todas essas instituições com uma formação regida por essa perspectiva. Ou seja, os cursos de formação, para atender à crescente demanda por profissionais com formação legal para o exercício da docência ${ }^{3}$, privilegiam o conceito de qualidade em que prevalece a lógica das competências, da supremacia dos conteúdos e do saber-fazer, em detrimento da formação que considere, além dessas perspectivas formativas, os fundamentos epistemológicos e científicos a direcionar todo o processo.

O discurso da qualidade da educação básica se configura, pois, como a lógica a encaminhar as ações do MEC em processo desde a promulgação da LDB e de modo mais vigoroso no decurso deste século, para enfrentar o grave problema da formação de professores e dos demais âmbitos da educação institucionalizada. Nesse sentido, toma corpo na política nacional, no início da primeira década do século XXI, a discussão sobre a expansão tanto de cursos como de redes de ensino e o envolvimento das instituições de ensino superior com a educação à distância (EAD) e, em todo esse quadro, a formação de professores. 
No quadro de ações do MEC para o encaminhamento da política de formação de professores e melhoria da educação básica, destaca-se a criação do Programa Pró-Licenciatura, em 2005, que vem compor o conjunto de ações do governo federal que institucionaliza, com o sistema UAB, "[...] os programas de formação de professores a distância como política pública de formação." (FREITAS, 2007, p. 1210). Convém, pois, registrar que este Programa, voltado exclusivamente para a formação inicial a distância de professores em serviço, operacionalizado em instituições públicas e privadas, com recursos do Fundo Nacional de Desenvolvimento da Educação (FNDE), insere-se no âmbito da expansão do ensino superior por meio de cursos a distância, correspondendo, assim, à lógica dos organismos internacionais.

A instituição do sistema Universidade Aberta do Brasil (UAB), em junho de 2006, evidencia a importância que a modalidade de ensino a distância passa a ter na política educacional, tornando-se, segundo Gatti, Barretto e André (2011, p. 64) “[...] um dos principais instrumentos de execução das políticas de formação em nível superior do MEC, ao lado do Programa de Apoio aos Planos de Reestruturação e Expansão das Universidades Federais (Reuni).” As autoras assinalam que em maio de 2011, havia a oferta de 930 cursos a distância, sendo $74,9 \%$ destinados à formação de professores. Destes, $38,7 \%$ estavam concentrados no Nordeste, sendo a região de maior cobertura.

O quadro da política de expansão da educação superior e, nesse contexto, da formação de professores para responder à crescente demanda nesse campo, se amplia por estas e outras medidas, como o lançamento pelo MEC, em abril de 2007, do Plano de Desenvolvimento da Educação (PDE), o qual embora não restrito ao espaço da formação, com este se relaciona ao desdobrar-se em outro Plano: o de Ações Articuladas (PAR). A formação de professores constitui uma das quatro dimensões em que se estrutura o PAR.

Como se pode observar, os Planos, Programas e outras ações do MEC voltados para a formação de professores, aqui sucintamente tangenciados, estruturam, juntamente com outras medidas, a política oficial do Estado no início deste século, a contemplar não só a Educação Superior, mas, sobretudo, a Educação Básica, desde que direcionados para qualificar em nível superior profissionais para esta etapa da educação. 
Todavia, como analisa Freitas (2007), o insuficiente atendimento à demanda de professores para a Educação Básica persiste como um problema estrutural; portanto, não conjuntural, nem exclusivamente emergencial, como quer a ótica oficial. Assim, as alternativas adotadas como a complementação pedagógica em licenciaturas paralelas (540 horas) ou aceleradas (120 horas) para graduados em cursos de bacharelato ou a concessão de bolsas para pós-graduandos para que após treinamento atuem como docentes em escolas públicas, não têm resolvido este grave problema. Ao invés disso, tendem a aprofundar o quadro da desprofissionalização dos professores pela flexibilização e aligeiramento da formação, como acentua a autora.

Um aspecto importante a considerar nos encaminhamentos da política de formação de professores é que passam a se delinear a partir de 2007 sob nova regulação: da Capes. Para tanto, o MEC alterou a estrutura desse órgão (Decreto $\mathrm{n}^{0}$ 6.316, de 20 de dezembro de 2007), na perspectiva de estruturar um sistema nacional de formação de professores, passando esse ator ao exercício de novas funções além das que habitualmente exerce na condução da política de pós-graduação. A partir daí, a Coordenação de Aperfeiçoamento de Pessoal de Nível Superior (Capes) assume a função de subsidiar o MEC na formulação de políticas e no suporte de atividades voltadas para a formação docente, inicial e continuada, em todos os níveis e modalidades, de modo mais marcante na educação a distância.

Como se depreende, pelas novas funções assumidas a atuação da Capes passa a ser primordial para a instituição, em 2009, da Política Nacional de Formação de Profissionais do Magistério da Educação Básica (Decreto $n^{\circ} 6.755$, de 29 de janeiro de 2009). Por força dessa Política caberá à Capes, entre outras atribuições, fomentar a "[...] oferta emergencial de cursos de licenciaturas e de cursos ou programas especiais dirigidos aos docentes em exercício há pelo menos três anos na rede pública de educação básica, que sejam: a) graduados não licenciados; b) licenciados em área diversa da atuação docente; e c) de nível médio, na modalidade normal." (BRASIL, 2009a, art. 11, inciso III).

Consideramos importante destacar, dos dez objetivos constantes no Decreto, os que se referem a promover: a melhoria da qualidade da educação básica; a equalização nacional das oportunidades de formação inicial e continuada dos profissionais do magistério em instituições de educação superior; a valorização do docente, median- 
te ações de formação inicial e continuada que estimulem o ingresso, a permanência e a progressão na carreira (BRASIL, 2009a, art. $3^{\circ}$, incisos I, III e V). Como alcançar os objetivos propostos nesse Decreto?

Ao ser instituída, a Política Nacional em referência estabelece formas de concretização desses objetivos. Assim, fica determinado que

[...] a Política Nacional de Formação de Profissionais do Magistério da Educação Básica cumprirá seus objetivos por meio da criação dos Fóruns Estaduais Permanentes de Apoio à Formação Docente, em regime de colaboração entre a União, os Estados, o Distrito Federal e os Municípios, e por meio de ações e programas específicos do Ministério da Educação. (BRASIL, 2009a, art. $4^{\circ}$ ).

Quanto a esse aspecto importa destacar, a nosso ver, a instituição oficial, por meio dos Fóruns Estaduais, de formas de controle social e de participação da sociedade civil na política de formação em vigor, desde que o regime de colaboração seja concretizado por meio de planos estratégicos formulados por esses Fóruns (art. $4^{\circ}, \S 1^{\circ}$ ).

Conforme referência feita, cabe à Capes como atual instância reguladora da Política Nacional de Formação fomentar a oferta de educação superior para professores em exercício na rede pública de educação básica. Para tanto, no âmbito dessa política está em implementação o Plano Nacional de Formação de Professores da Educação Básica (PARFOR). Este Plano integra o PAR no conjunto amplo de ações do PDE. Estará o MEC, com essa nova forma de regulação pela Capes, e com a participação institucionalizada de controle social por meio da Política Nacional de Formação dos Profissionais do Magistério da Educação Básica, objetivando superar a fragmentação que vem marcando o desenvolvimento das políticas educacionais?

\subsection{Programas Especiais para a Formação Docente no Estado do Maranhão}

O panorama delineado na seção anterior, que trata da expansão da educação superior nas últimas décadas no Brasil e no Maranhão, apontando que neste estado os maiores percentuais de elevação desse nível de educação ocorreram nos cursos de licenciatura, nesta seção discutiremos questões relacionadas à formação de professores, bem como apresentamos um breve esboço de programas 
desenvolvidos por Instituições Públicas de Ensino Superior antes e após a promulgação da LDB de 1996.

A expansão do sistema público de ensino, ocorrida de modo mais acentuado a partir da década de 1970 do século XX, consequência do movimento de ampliação do acesso à escola e do prolongamento da escolaridade obrigatória, incorporou de forma mais intensa grupos de origem social diversa dos grupos sociais até então em processo de escolarização, portadores de "[...] saberes socialmente construídos na prática comunitária." (FREIRE, 1996, p. 33). Os professores desses estabelecimentos públicos atendiam estudantes da classe média, cujo capital cultural era de certa forma compatível com os referenciais veiculados nos seus processos formativos.

Nos estabelecimentos escolares situados nas periferias dos centros urbanos e nas áreas rurais, os professores nem sempre eram portadores da qualificação mínima, tanto em nível de escolarização (Ensino Médio na modalidade Normal), quanto em conteúdos e metodologias capazes de promover a aprendizagem desses novos grupos sociais.

Nesse contexto, a escola demandava outros elementos para melhor atender os alunos, e as verbas públicas destinadas à educação nem sempre eram suficientes para dar conta dessas necessidades emergentes, embora os grupos organizados da sociedade permanecessem em constante reivindicação por melhores condições materiais e profissionais de trabalho. A essas questões somava-se a denúncia sistemática da pouca participação dos professores na concepção de seu próprio trabalho, ou seja, faltava-lhes autonomia ao mesmo tempo em que estes recebiam pacotes pedagógicos, provenientes da esfera federal, estadual ou mesmo municipal, elaborados por técnicos de alto nível para serem executados na escola. Presentemente, vários programas ainda chegam às mãos dos professores em várias situações sem haver sequer a tradução do conteúdo dessas propostas, gerando um descompromisso com os resultados obtidos por essas experiências. Esse conjunto de situações e outras não apontadas neste texto contribuem para que os resultados das avaliações de desempenho dos alunos, obtidos por meio de programas de larga escala - Sistema Nacional de Avaliação da Educação Básica (SAEB), Provinha Brasil, Exame Nacional do Ensino Médio (ENEM) e outras - atestem que parcela significativa de estudantes tanto do ensino fundamental quanto do ensino médio não demonstrem ter desenvol- 
vido competências e habilidades elementares de leitura e em relação à Matemática apresentem grandes deficiências. Nos marcos estabelecidos pelas reformas educativas, esse desempenho é incompatível com as exigências postas pela globalização da economia em que o trabalhador brasileiro sem o domínio das competências básicas não apresentem os requisitos para integrarem o processo competitivo.

Quase sempre os baixos índices de aprendizagem dos alunos da educação básica são debitados à falta de formação dos professores, embora se saiba que esta não constitua a única razão desses resultados, pois, entre estes, encontram-se as condições de trabalho, salários, apoio técnico pedagógico, além de questões ligadas às condições de vida dos alunos e de suas famílias. Dessa forma, a temática da formação de professores tem sido continuamente discutida em vários âmbitos da sociedade brasileira, envolvendo atores de diversos matizes ideológicos.

Nos anos de 1990 do século XX, esse debate foi intensificado por constituir "[...] o modelo de expansão da educação superior.", conforme já assinalado na seção anterior, implementado nessa década no âmbito das reformas de Estado e subordinado às recomendações dos organismos internacionais. (FREITAS, 2007, p. 1208).

Esse debate instaurado na sociedade brasileira com o aporte de pesquisadores internacionais evidencia, na ótica de Freitas (2002, p. 138), "[...] a existência de dois movimentos que se entrelaçam de forma contraditória.".

De um lado, o movimento de educadores iniciado a partir do final da década de 1970 e início da de 1980 no interior de um movimento mais amplo pela democratização da sociedade, mantendo-se ao longo das últimas quatro décadas na defesa de uma concepção emancipadora da educação que orienta os processos formativos do profissional desta área da educação assentados na docência que constitui a identidade dos profissionais da educação.

A Associação Nacional pela Formação dos Profissionais da Educação (ANFOPE), expressão maior desse movimento, ao longo de três décadas juntamente com outras associações científicas, vem contribuindo mediante a afirmação dos princípios que defende para a formulação, implementação e avaliação das políticas de formação e de valorização dos profissionais da educação. Em linhas gerais, te- 
mos a seguir alguns princípios defendidos pela ANFOPE (BRZENZISKI, 2011, p. 6):

- Sólida formação teórica e interdisciplinar sobre o fenômeno educacional e seus fundamentos históricos, políticos e sociais;

- Unidade teórica prática atravessando todo o curso;

- Compromisso social e profissional da educação, com ênfase na concepção sócio histórica;

- Gestão democrática entendida como superação do conhecimento de administração enquanto técnica;

- Incorporação da concepção de formação continuada visando ao aprimoramento do desempenho profissional;

- Avaliação permanente dos cursos de formação dos profissionais da educação como responsabilidade coletiva.

A intensa discussão desses princípios em inúmeros fóruns nacionais possibilitou a sua incorporação em projetos pedagógicos de cursos de licenciatura construídos na década de 1990 e início dos anos 2000.

No entanto, esse panorama passa por alterações substanciais com a emissão das Resoluções $\mathrm{CNE} / \mathrm{CP} \mathrm{n}^{0}$. 1, de 18 fevereiro de 2002 e n$^{\circ} .2$, de 19 de fevereiro de 2002, que tratam das Diretrizes Curriculares Nacionais para Cursos de Graduação e cargas horárias de cursos de licenciatura.

De outro lado, a partir da década de 1990, a ação do Estado tornou-se mais intensa com o desencadeamento de reformas educativas, sob a égide do ideário neoliberal, recomendadas por organismos internacionais. Dessa forma, a educação assume posição basilar na preparação do trabalhador para o mercado de trabalho e a escola passa a ser o alvo principal das políticas educacionais para onde converge um conjunto de Programas. Nesse contexto, de acordo com Freitas (2002), a formação de professores assume papel estratégico na concretização das reformas educativas direcionadas para a melhoria da capacitação dos recursos humanos necessários à garantia da competitividade dos mercados.

As análises dos ordenamentos legais pós LDB/1996, emanados das reformas educativas, apontam o caráter técnico-instrumental da formação de professores direcionado para a solução de problemas 
que emergem do cotidiano escolar (FREITAS, 2002), o que denota um esvaziamento de estudos do conteúdo teórico da ciência da educação.

As concepções que embasam as determinações legais, sobretudo as discussões contidas nos pareceres emitidos pelo CNE, incorporam discussões realizadas por pesquisadores nacionais e internacionais de uma literatura pedagógica (SCHÖN, 2000; ZEICHNER, 1993; PERRENOUD, 1993, entre outros), disseminada no meio educacional brasileiro.

A promulgação da Lei 9.394/96, que exigia a formação superior para os professores de todos os níveis e modalidades da educação básica, e a criação do FUNDEF permitindo aos municípios brasileiros a viabilização dessa determinação legal em várias localidades, propiciaram dar início a cursos de formação de professores. No entanto, no Maranhão, ainda em 1993, a Universidade Estadual do Maranhão (UEMA) implantou o Programa de Capacitação Docente do Sistema Educacional do Maranhão (PROCAD), com o objetivo de graduar em cursos de Licenciatura Plena, com funcionamento parcelado, isto é, nos meses de férias escolares, professores em exercício nas escolas públicas. Este Programa atuou em diversas regiões do Maranhão e graduou um número significativo de professores, sendo transformado em Programa de Qualificação Docente (PQD), mantendo a mesma estrutura.

Em sua substituição, foi organizado o Programa Darcy Ribeiro, voltado para a formação de professores nas áreas de Matemática, Química, Física e Biologia, cujo déficit de professores é bastante elevado nas escolas estaduais e municipais. Com a criação do PARFOR/MEC, o Programa em pauta passou a ser viabilizado com recursos federais.

À semelhança do que aconteceu na UEMA, a Universidade Federal do Maranhão (UFMA) criou em 1998 o Programa Especial de Formação de Professores para a Educação Básica (PROEB), com atuação em vários municípios maranhenses. $\mathrm{O}$ curso funciona nos finais de semana em regime intensivo, objetivando graduar em cursos de licenciatura plena professores de escolas públicas mediante convênio estabelecido entre a Prefeitura Municipal e a UFMA. O Instituto Federal de Educação Tecnológica do Maranhão (IFMA) constitui outro espaço formativo voltado para a educação básica. Desde 
1999 oferece cursos de licenciatura em Matemática em regime parcelado/intensivo para professores de municípios maranhenses.

Cabe destacar que as três Instituições Públicas de Ensino Superior do Maranhão viabilizaram os cursos oferecidos mediante convênios estabelecidos com prefeituras municipais, utilizando recursos provenientes inicialmente do FUNDEF, que facultava aos municípios aplicarem $60 \%$ do montante recebido na capacitação de professores leigos.

Considerando a escassez de professores portadores de licenciatura plena para atuarem na educação básica, outras instituições públicas de outros estados estenderam seus cursos a municípios maranhenses, como a Universidade Estadual do Piauí (UESPI) e a Universidade do Vale do Acaraú (UVA). Ressalte-se que a UVA permanece no Maranhão oferecendo cursos de diversas modalidades, mantidos com mensalidades pagas pelos próprios alunos. Torna-se oportuno destacar que outras instituições atuam em municípios maranhenses de forma presencial ou a distância, entre as quais se destacam as instituições confessionais, que desenvolvem cursos de Pedagogia Cristã.

A literatura sobre formação de professores vem sistematicamente apontando o caráter aligeirado desses cursos ministrados de forma intensiva em que os alunos ficam impossibilitados de realizar estudos aprofundados sobre questões relevantes da educação brasileira, o que fatalmente tem resultado no comprometimento da qualidade da educação básica. Outro aspecto destacado por pesquisadores tem sido as condições em que ocorrem esses cursos, que vão desde a inexistência de infraestrutura nos locais de sua realização, aos complexos processos de aprendizagem que envolvem cada participante desses cursos.

\section{O PROFEBPAR na UFMA}

Conforme já apontado, foi criado, em 2007, o PAR, objetivando articular as ações apoiadas técnica e financeiramente pelo MEC, tendo em vista a implementação do Plano de Metas Compromisso Todos pela Educação (Decreto $n^{\circ} 6.094$, de 24 de abril de 2007). A criação desse Plano partiu de um diagnóstico realizado em colaboração com o ente federado, no qual estão apontadas as medidas mais condizentes para a gestão do sistema e voltadas para a melhoria da qualidade da educação básica. 
Cabendo aos Estados e Municípios a execução do PAR, o Estado do Maranhão, ao aderir ao Programa, compromete-se com a implementação das quatro ações previstas no Decreto ${ }^{\circ}$ 6.094/2007, quais sejam: gestão educacional, formação de professores e profissionais de serviços e apoio escolar, recursos pedagógicos e infraestrutura física.

Inegavelmente o PAR, enquanto proposta ampla que se estende a todo o país, intermediado pelos entes federados que se incumbem da sua implementação, recoloca, de certo modo, a responsabilidade da União com o desenvolvimento de políticas públicas voltadas para a educação (ALBUQUERQUE, 2012). Além disso, pode desencadear um processo de construção coletiva, inicialmente tênue, mas capaz de propiciar um entrelaçamento mais consistente no que diz respeito à elaboração de diagnóstico e planejamento que, despontados das análises locais, possam reverter em benefício dos municípios proponentes nos diversos espaços sociais, extrapolando, pois, o educacional.

Adotando sistemática operacional semelhante, o Governo Federal institui a Política Nacional de Formação de Profissionais do Magistério da Educação Básica (Decreto ${ }^{\circ}$ 6.755, de 29 de janeiro de 2009), objetivando organizar a formação inicial e continuada dos profissionais do magistério para as redes públicas da educação básica, em regime de colaboração firmado entre a União, os Estados, o Distrito Federal e os Municípios.

Com base nesse Decreto, o MEC institui o PARFOR (Portaria Normativa $\mathrm{n}^{\circ}$ 09, de 30 de junho de 2009), visando a cooperação mútua técnico-operacional entre as partes, com a finalidade de promover a formação de professores das redes públicas de educação básica. Formação essa a cargo das Instituições Públicas de Educação Superior (IPES), a ser realizada após a formalização de Termo de Adesão aos Acordos de Cooperação.

No Maranhão, mais especificamente, na UFMA, o PARFOR foi criado em 2009, e intitulado de Programa de Formação de Professores da Educação Básica (PROFEBPAR), em parceria com alguns municípios e com a Secretaria de Estado de Educação do Maranhão (SEDUC), situando-se, burocraticamente, na Assessoria de Interiorização (ASEI)/UFMA. Oferece cursos de $2^{\mathrm{a}}$ Licenciatura e $1^{\mathrm{a}} \mathrm{em}$ Pedagogia, conforme previstos na legislação citada, em municípios pólo ${ }^{4}$, com 689 matrículas. 
Diante dessa nova fase do planejamento governamental na tentativa de dar conta, de certa forma, dos problemas da educação no país, perguntamos: Será que esses Programas podem reverter situações antigas, como a erradicação de professores leigos, principalmente na região Nordeste, onde os índices ainda são na ordem de $44 \%$ e no Maranhão, de $52 \%$ ? Será que propostas apresentadas a partir de um traçado idealizado sob as vistas do MEC e aceitas sem maiores reflexões pelas instituições educacionais regionais e locais, visto acenarem com aportes financeiros atingirão a eficácia a que se propõem? Será que ações emergenciais e isoladas do cotidiano das nossas escolas serão suficientes para reverter o quadro em discussão? E a modalidade de aulas ministradas somente nos finais de semana, em alguns municípios-sede, ultrapassa a movimentação que desencadeia, tanto nas instituições provedoras de professores das capitais, quanto nas localidades em que residem os professores-alunos?

Essas preocupações surgem no cotidiano, aliás, espaço vital na construção do conhecimento, visto constituir-se lócus da formação docente, por onde se movem e se cruzam convergências e divergências, e onde adquire substância o ambiente escolar, tão necessário para o melhor desempenho de todos os envolvidos com a educação.

Como profissionais que transitam numa linha de tensão "[...] entre valores, atitudes e comportamentos que circulam nos meios de comunicação, em dada comunidade, a família e a escola [...]" (GATTI; BARRETO; ANDRÉ, 2011, p. 25), bem como modismos das mais diversas formas, que atingem também os alunos, os professores sentem-se pressionados a assumirem novas atitudes de caráter subjetivo, mesmo que construídas a partir de experiências profissionais, mas que passam a adquirir significado específico para cada professor.

Nesse sentido, constitui mais um desafio o assumir maior grau de comprometimento com a personalização dos sujeitos envolvidos com a educação, a começar pelos ingressantes em cursos de formação de professores. Considerada "[...] um investimento formativo do humano, seja na particularidade da relação pedagógica pessoal, seja no âmbito da relação social coletiva [...]", a educação centra-se no "[...] respeito radical à dignidade humana desses sujeitos [...]" (SEVERINO, 2009, p. 160). 
Parece-nos que salientar esse aspecto no qual a educação está intrinsecamente ligada à humanização mostra-se essencial para qualquer discussão sobre outros de caráter mais institucional, visto demarcar com que tipo de educação estamos comprometidas, portanto, como nos identificamos frente às finalidades da educação.

Preocupa-nos, pois, o processo desencadeado institucionalmente pós LDB, para o cumprimento dos aspectos legais, de modo especial os relacionados com a modalidade especial de formação docente em discussão.

Cabe salientar, a percepção, numa primeira vista, de uma conexão entre as indagações aqui colocadas, e a Portaria Normativa ${ }^{\circ}$ 09/2009, logo no seu art. $2^{\circ}$, inciso I, quando estimula a ampliação das matrículas oferecidas pelas IPES em cursos de licenciatura e de pedagogia dando-lhe "[...] preferentemente a destinação emergencial de vagas para professores em exercício na rede pública de educação básica."; e no inciso II do mesmo artigo, ao enfocar que o fomento às IPES dar-se-á para "[...] apoio à oferta de cursos de licenciatura e programas especiais emergenciais destinados aos docentes em exercício na rede pública de educação básica e à oferta de formação continuada [...]" (BRASIL, 2009b).

A insistência do documento oficial nos termos emergencial/ emergenciais leva-nos a relacioná-los ao caráter crônico que permeia grande parte dos problemas dos quais se ressente a educação brasileira, como a má qualidade do ensino, a necessidade de extinção de professores leigos, enfim, problemas de natureza estrutural que podem, sob o signo da emergência, camuflar ou mesmo retardar um processo de educação mais voltado para a real superação dessas questões, a ser construído sem conotação de tornar-se um grande evento mais centrado nos meios do que nos próprios resultados.

Enfrentamos a crise da urgência. E a formação de professores, como vimos, está aí incluída, principalmente se levada em consideração a necessidade de expansão da rede escolar da educação básica, a fim de atender ao princípio constitucional, indiscutivelmente investido da maior importância, que proclama o direito de todos à educação e a obrigatoriedade da universalização desse nível de educação.

Por outro lado, o contexto mostra-se propício ao surgimento de soluções mágicas, assim como muitas críticas são apontadas, cau- 
sando certa inquietação e efervescência, principalmente entre os que militam no setor educacional, tendo como pano de fundo não tão visível, mas presente, a necessidade de adequar o sistema de educação do país às exigências do processo de produção do capital que não leva em consideração os contextos históricos e as pessoas que neles vivem e transitam.

Tomando como referência a UFMA, cabe enfocar a posição assumida ao concordar com a ampliação do PROFEBPAR em municípios maranhenses, desde que algumas ações transformadoras fossem postas em prática. Somente para exemplificar, a apontada em relação ao ingresso dos professores-alunos no Programa, de modo a sanar dificuldades de aprendizagem possivelmente decorrentes de precária formação escolar básica, acompanhada de proposta "[...] para uma preparação prévia que oportunize o ensino aprendizagem dos conteúdos ministrados." (UNIVERSIDADE FEDERAL DO MARANHÃO, 2012), dentre outras, considerando a forma de seleção eletrônica adotada pelo Programa, não permitindo diagnosticar conhecimentos anteriores, de modo a respaldar melhor desempenho no Curso.

Se levarmos em conta que o Programa objetiva melhorar a qualidade da educação básica ao investir na formação de professores, ações desse quilate merecem ser consideradas, pois o investimento na formação docente em cursos de licenciatura oferecida há que ir além da titulação, de modo a tornar-se um investimento competente e capaz de "[...] expressar sensibilidade às condições histórico-culturais da existência dos sujeitos envolvidos na educação." (SEVERINO, 2009, p.161).

Dando continuidade ao cruzamento das questões aqui colocadas com as do PROFEBPAR, no que se refere à sistemática operacional adotada para a realização dos cursos de licenciatura nos municípios atendidos pelo Programa, valemo-nos dos estudos de Santos Neta (2012), que traçam as linhas gerais do cenário em que os cursos de Pedagogia são ministrados: cada disciplina teórica obedece a uma agenda que coloca 04 encontros (01 por mês) com duração de 15 horas cada, realizados aos sábados e domingos, nos municípios sede, em escolas municipais ou estaduais, que nem sempre possuem uma estrutura adequada, sendo disponibilizadas com salas de aula quentes e que ficam lotadas durante as aulas do Curso. Segunda a autora, essas escolas não dispõem de espaços para atividades, como 
bibliotecas, salas de vídeo e auditórios, entre outros. Por outro lado, a agenda escolar marca a ministração de 4 ou 5 disciplinas por mês. Nos seus estudos, enfoca igualmente problemas detectados e relacionados com o ingresso dos professores-alunos no Programa, carecendo de preencher lacunas, possivelmente oriundas da formação básica desses professores, questão apontada como dificultadora da aprendizagem.

Situação essa adicionada ao fato de que a maioria dos professores-alunos trabalha intensamente por toda a semana não sobrando tempo para o preparo das atividades propostas para cada disciplina, como também para o amadurecimento e a reflexão sobre as temáticas apresentadas pelos professores formadores. Estes, por sua vez, sobrecarregam-se de trabalho, enfrentam dificuldades com o deslocamento para os municípios sede e, muitas vezes, frustram-se e frustram seus alunos diante da gama de problemas enfrentados ou a enfrentar.

Como colocado anteriormente, percebemos que programas dessa natureza precisam de um acompanhamento rigoroso, no sentido de sanar, no decorrer do processo, deficiências tais como apontadas e que apenas foram exemplificadas neste texto.

Concordando com Severino (2009, p. 160), ao apontar que "[...] a educação não pode ser concebida apenas como um processo institucional, seu lado visível, mas, fundamentalmente, como um investimento formativo do humano, seja na particularidade da relação pedagógica pessoal, seja no âmbito da relação social coletiva.", cabe encerrar dizendo que se o processo educativo se desvia desse caminho, há que sejam envidados todos os esforços para redimensioná-lo, de modo a ser reconstruído tendo como primeira finalidade a formação "[...] do humano no homem."

Apenas esboçamos, aqui, algumas das nossas inquietações que, ao lado de outras mais, constituem o foco dos estudos por nós já realizados ou em realização, no Programa de Pós-Graduação em Educação (PPGE) da UFMA.

\section{REFERÊNCIAS}

ALBUQUERQUE, S. V. de. Formação continuada de professores no Plano de Ações Articuladas (PAR): a implementação no Município de Santa Inês/MA. In: ENCONTRO NACIONAL DE DIDÁTICA E 
PRÁTICAS DE ENSINO, 21., 2012, Campinas. Anais... Campinas: UNICAMP, 2012.

BRASIL. Ministério da Educação. Instituto Nacional de Estudos e Pesquisas Educacionais Anísio Teixeira. Censo da Educação Superior. Brasília, DF, 1996.

. Decreto $\mathrm{n}^{0} 6.755$, de 29 de janeiro de 2009. Institui a Política Nacional de Formação de Profissionais do Magistério da Educação Básica, disciplina a atuação da CAPES no fomento a programas de formação inicial e continuada. Diário Oficial da União, Brasília, DF: Casa Civil da Presidência da República, 2009a.

. Ministério da Educação. Portaria Normativa $n^{\circ} 09$, de 30 de junho de 2009. Institui o Plano Nacional de Formação dos Professores da Educação Básica. Diário Oficial da União, Brasília, DF, 2009b. Disponível em:<http://portal.mec.gov.br/dmdocuments/ port normt 09 300609.pdf $>$. Acesso em:

. Ministério da Educação. Instituto Nacional de Estudos e Pesquisas Educacionais Anísio Teixeira. Censo da Educação Superior. Brasília, DF, 2011.

BRZENZISKI, I. (Org.). ANFOPE em movimento: 2008-2010. Brasília, DF: Liber Livros: Anfope: Capes, 2011.

FREIRE, P. Pedagogia da autonomia: saberes necessários à prática educativa. São Paulo: Paz e Terra, 1996. (Coleção Leitura).

FREITAS, H. C. L. de. A reforma do Ensino Superior no campo da formação dos profissionais da educação básica. Educação e Sociedade, São Paulo, n. 68, p. 17-44, 1999.

. Formação de professores no Brasil: 10 anos de embate entre projeto de formação. Educação e Sociedade, São Paulo, v. 23, n. 80, set. 2002.

. A (nova) política de formação de professores: a prioridade postergada. Educação e Sociedade. São Paulo, v. 28, n. esp. 100, p. 1203-1230, out. 2007.

GATTI, B. A.; BARRETTO, E. S. de S.; ANDRÉ, M. E. D. de A. Políticas docentes no Brasil: um estado da arte. Brasília, DF: UNESCO, 2011.

PERRENOUD, P. Práticas pedagógicas, profissão docente e formação: perspectivas sociológicas. Lisboa: Publicações D. Quixote, 1993. 
SANTOS NETA, A. R. Professor-Aluno: duas faces da mesma moeda. In: ENCONTRO DE EDUCADORES DO MARANHÃO, 5., 2012, São Luís. Anais... São Luís: PPGE;UFMA, 2012. GT 6 - Formação de Educadores.

SAVIANI, D. O Plano de Desenvolvimento da Educação: análise do projeto do MEC. Educação e Sociedade. São Paulo, v. 28, n. esp. 100, p. 1231-1255, out. 2007.

SCHON, D. Educando o profissional reflexivo: um novo design para o ensino e a aprendizagem. Porto Alegre: ARTMED, 2000.

SEVERINO, A. J. Humanismo, personalismo e os desafios sociais da educação contemporânea. Revista de Educação Pública, Cuiabá, v. 18, n. 36, p. 155-164, 2009.

SILVA JR., J. dos R. Reforma da educação superior: a produção da ciência engajada ao mercado e de um novo pacto social. In: MANCEBO, D. et al. Políticas e gestão da educação superior: transformações recentes e debates atuais. São Paulo: Xamã; Goiania: Alternativa. 2003.

UNIVERSIDADE FEDERAL DO MARANHÃO. Departamento de Educação II. Exposição de Motivos sobre a ampliação do PROFEBPAR na UFMA. São Luís, 2012.

ZEICHNER, K. Traditions of Practice in U. S. Teacher Education Programs. Teaching and Teacher Education, [S. 1.], v. 9, n. 1, p. 1-13, 1993.

\section{NOTAS}

1 De fato, dos anos de 1990 em diante, vários países latino-americanos, entre estes o Brasil, empreendem reformas de alcance sócio-político-econômico, principalmente, para adequar-se aos imperativos de uma reorganização do mundo capitalista que já se vinha gestando nos anos de 1980, com o governo Thatcher, na Inglaterra, em decorrência da crise que abalava esse sistema desde os anos de 1970, mas prenunciada uma década antes. Daí espraiam-se as reformas encaminhadas pelas ideias neoliberais, reforçadas também pelo poder hegemônico dos Estados Unidos por meio de um governo, tal como o inglês, declaradamente conservador - Ronald Reagan - eleito em 1980.

2 Essa análise vem demonstrar que os rumos da política educacional em geral e, neste caso particular, a de formação de professores constituem uma resposta aos compromissos assumidos pelo Brasil (e demais países signatários da Declaração) durante a Conferência Mundial sobre Educação para Todos, realizada em março de 1990, em Jomtien-Tailândia, promovida pelo Fundo das Nações Unidas para a Infância (UNICEF), Programa das Nações Unidas para o Desenvolvimento (PNUD), UNESCO e Banco Mundial. A qualidade da educação básica passa, então, a constituir um tema recorrente não só no âmbito do Ministério da Educação e Cultura (MEC), mas em setores da sociedade, ora em apoio às 
ideias desse Ministério, ora em contraposição a elas, neste caso por meio de movimentos de educadores envolvidos com a melhoria da educação básica, distantes, portanto, da concepção defendida por aqueles organismos internacionais, como referimos.

3 Em artigo publicado em 2007, Freitas (2007) relata que havia cerca de 184 mil funções docentes dos anos/séries finais do ensino fundamental e 56 mil funções no ensino médio da rede pública em todo o país que eram ocupadas por profissionais sem a formação legal exigida para a função.

4 Municípios pólo no Maranhão: Bom Jesus das Selvas, Buriti Bravo, Caxias, Codó, Coroatá, Grajaú, Humberto de Campos, Imperatriz, Lago da Pedra, Magalhães de Almeida, Nina Rodrigues, Pindaré-Mirim, Poção de Pedras, Santa Inês, São José de Ribamar, Santa Quitéria do Maranhão, Timbiras e Vargem Grande. 